\title{
Morphological and genetic variability among Ecklonia cava (Laminariales, Phaeophyceae) populations in Korea
}

\author{
Dong Mun Choi ${ }^{1,2}$, Young Wook Ko ${ }^{1}$, Rae-Seon Kang ${ }^{1}$ and Jeong Ha Kim ${ }^{2, *}$ \\ ${ }^{1}$ Biological Oceanography and Marine Biology Division, Korea Institute of Ocean Science \& Technology, Ansan 426-744, Korea \\ ${ }^{2}$ Department of Biological Sciences, Sungkyunkwan University, Suwon 440-746, Korea
}

Ecklonia cava Kjellman is a common kelp found in shallow subtidal in warm-temperate waters in the northwest Pacific Ocean. This species has shown substantial morphological variation along with subsistence in different locations and local environments. We quantified the magnitude of morphological variation of E. cava from six populations along $700 \mathrm{~km}$ of coastline from Jeju Island to Dokdo in Korea. In addition, we examined genetic distance among the populations using random amplified polymorphic DNA (RAPD) analysis. Most morphological characteristics investigated were significantly different among locations. Multivariate analyses indicated two phenetically distinct groups (nearshore, sheltered vs. offshore, exposed), indicating wave exposure with turbidity are presumably major factors for the separation. With RAPD data, results of Nei's diversity $(H)$ and AMOVA showed considerable variations in within- and between-populations. Pairwise $\Phi_{\mathrm{ST}}$ and $\mathrm{N}_{\mathrm{m}}$ values indicated moderate gene flow between the six locations. Results of Nei's analysis revealed three genetically distinct groups, not consistent with the morphological groupings, indicating that a time gap may exist between morphological and genetic variations. This study also suggests dispersal distance of this kelp may be longer than what is commonly thought and genetic similarity in the populations was largely reflected by the direction of ocean current rather than just geographical distance.

Key Words: Ecklonia cava; genetic variation; kelp; morphology; phenotype; RAPD

\section{INTRODUCTION}

Ecklonia cava Kjellman is a perennial brown alga, one of the major components of kelp forests in the northwestern Pacific regions. Generally growing on shallow rocky subtidals $(<5-25 \mathrm{~m})$, the kelp often forms dense subsurface canopies at the sites exposed to northern swells (Kang et al. 1993, Serisawa et al. 2002a), and thus providing an important nursery and breeding ground for marine resource species (Largo and Ohno 1993). The distribution of well-developed populations covers southern Korea (from Jeju Island to Dokdo) and southern Japan (from the central part of Honshu to the westernmost part of Kyushu), considered endemic to warm-temperate waters in Korea and Japan (Kang et al. 1993, 2001, Terawaki and Arai 2004).

Within its geographic range, E. cava exhibits considerable morphological variation among plants, apparently correlated with local environmental conditions (Serisawa et al. 2001, 2002a). Morphological variation influenced by characteristic habitat features is common among brown algae (e.g., Rice and Kenchington 1990, Wernberg et al. 2003, Macinnis-Ng et al. 2005, Matson and Edwards 2006) and thereby makes identification of species difficult on
(9) $\$$ This is an Open Access article distributed under the terms of the Creative Commons Attribution Non-Commercial License (http://creativecommons.org/licenses/by-nc/3.0/) which permits unrestricted non-commercial use, distribution, and reproduction in any medium, provided the original work is properly cited.
Received April 12, 2015, Accepted May 28, 2015

*Corresponding Author

E-mail: jhkbio@skku.edu

Tel: +82-31-290-7009, Fax: +82-31-290-5919 


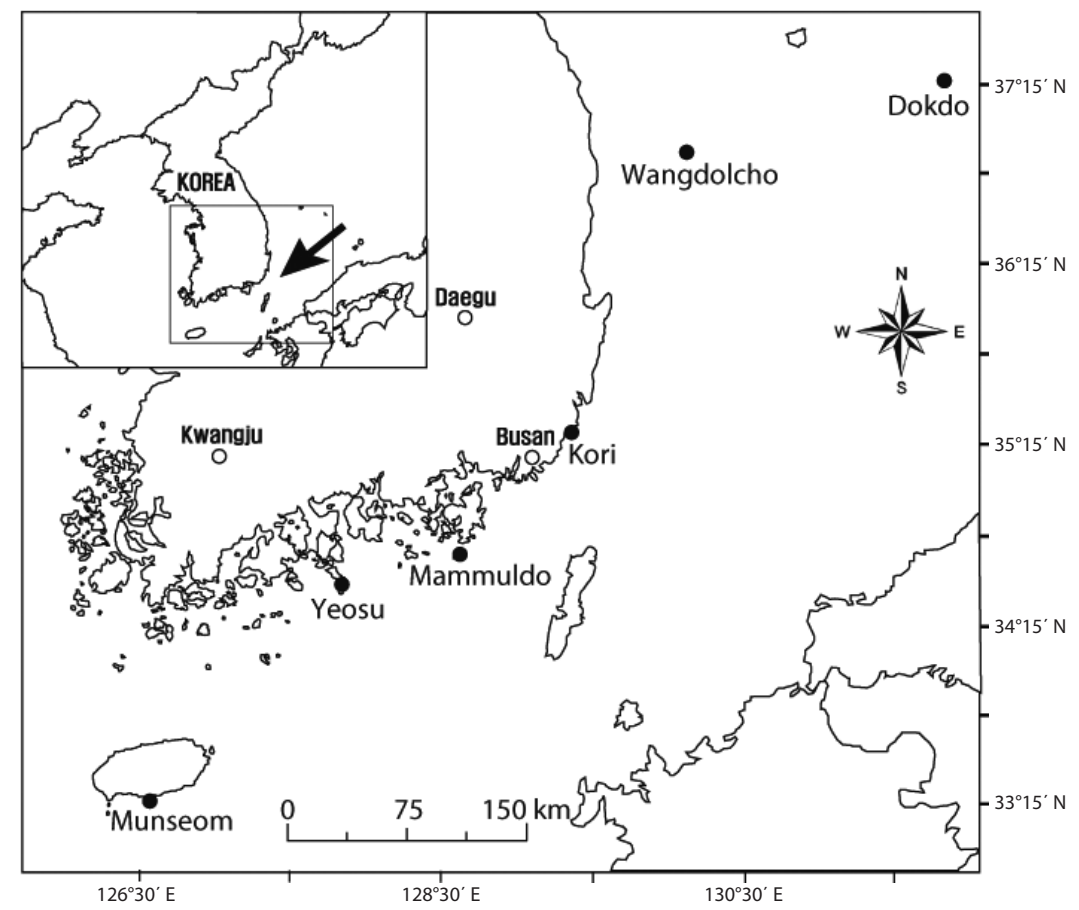

Fig. 1. The sampling localities of the six Ecklonia cava populations.

the basis of external appearance (Russell 1978). Several theoretical and empirical reports suggest morphological differences among populations are caused by geographical separation as genetic exchange among populations becomes restricted and are exposed to grossly different environmental conditions (Kusumo and Druehl 2000). When genetic variations occur, reproductive performance and survival against stochastic events are significantly improved (Frankham 1996, Frankham et al. 2002). The patterns of genetic variation and population structure are very important to the ecology and evolution research, allowing greater understanding into the transmission of genes from generation to generation, and a prediction of long-term survival and the continued evolution of populations and species (Sosa et al. 2002, Bouza et al. 2006). Therefore, molecular makers are a valuable tool in understanding and predicting the mechanisms that cause interpopulational genetic differentiation.

Random amplified polymorphic DNA (RAPD) is a method that reveals genetic variability within a species and elucidates differences at the population level in diverse marine plants such as microalgae (Gómez and González 2001, 2004), seagrasses (Larkin et al. 2006), and seaweeds (Bouza et al. 2006). The strengths and weaknesses of RAPD method have been widely debated (e.g., Hadrys et al. 1992, Sunnucks 2000). Although some re- searches have been performed (e.g., Van Oppen et al. 1996, Coyer et al. 1997), the use of RAPD for small-scale geographical research is inadequate and, when a large number of markers are included and the analysis is restricted to taxa in which band homology assessments are confidently made (conspecific populations). The results of RAPD assessments may be successfully incorporated into evaluation of inter- and intrapopulation differentiation of natural populations (see reviews in Bouza et al. 2006).

Our preliminary surveys for E. cava were conducted along a $180 \mathrm{~km}$ length of southern Korean coast between 2003 and 2004, indicated that the external morphology of adult E. cava sporophytes was highly variable depending on habitat locations. Some local populations caused taxonomic confusion with other local Ecklonia species (i.e., Ecklonia kurome Okamura and Ecklonia stolonifera Okamura). Historically, E. cava has been a major species comprising kelp forests in warm water environments around Jeju Island, stretching to northern parts of the Korean coast (Lee and Kang 2001). The objective of this research is to quantify the magnitude of morphological variation, and to examine the genetic distance of E. cava populations across the geographic range in Korea using an appropriate molecular tool. In addition to providing basic information on the population structure of this 
ecologically important kelp, our results will be useful in understanding E. cava metapopulation dynamics and also provide valuable tips to restoration programs. E. cava populations are gradually disappearing near Korea (e.g., Chung et al. 1998, Kang 2010), increasing the importance of this work.

\section{MATERIALS AND METHODS}

\section{Sampling}

Sporophytes of E. cava reproduce in early autumn. Only the basal part remains after reproduction and grows again from early winter (Largo and Ohno 1993). To avoid the reproduction period and remove the data noise caused by the seasonal growth pattern, all samples were collected during one season (i.e., Spring: March 2007 to May 2007). Six locations were selected: one from Munseom of Jeju Island, two along the southern coast of Korea and three locations from East Sea (Table 1, Fig. 1). All locations within the study area were selected on the basis of accessibility and proximity. These six locations span $4^{\circ}$ north-south and $5^{\circ}$ east-west, and they cover $\sim 700 \mathrm{~km}$ of coastline including the geographic range of E. cava from its northern limit in Korea to Jeju Island. Within each location, twenty mature thalli, differentiated into branching laterals ('stage 3' as defined by Kirkman 1981) were randomly chosen from E. cava habitats at 5-25 $\mathrm{m}$ depth subtidal (except Dokdo where only 16 individuals were sampled) and harvested as close as possible to the hold-

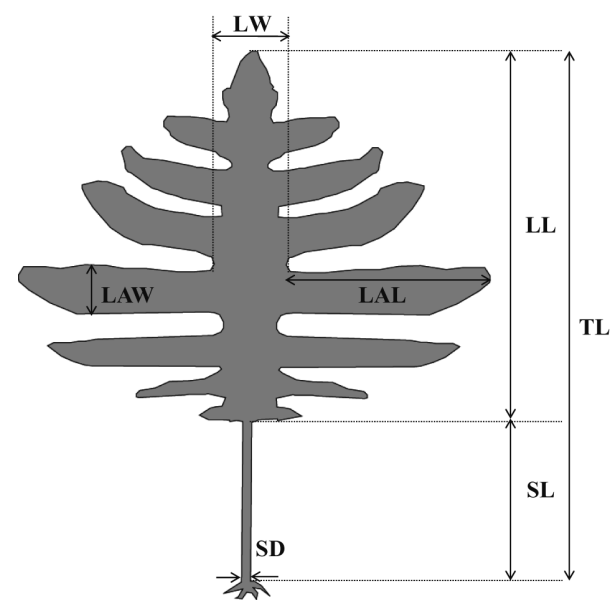

Fig. 2. Morphological characters measured. $T L$, total length; $S L$, stipe length; SD, stipe diameter; LL, lamina length; LW, lamina width; $\mathrm{LAL}$, lateral length; LAW, lateral width.

fast using a diving knife. We attempted not to collect individuals grown too close each other to ensure a level of independence in morphological and genetic identity. The collected specimens were brought to the surface, drained, bagged, and transported to the laboratory in dry ice, then refrigerated until processing.

\section{Morphological characteristics}

Nine common morphological parameters were measured for each thallus (Fig. 2). Morphological measurements includes total length, thallus dry weight, stipe

Table 1. Sampling locations

\begin{tabular}{|c|c|c|}
\hline Location & Code & Habitat \\
\hline \multicolumn{3}{|l|}{ Jeju Island } \\
\hline $\begin{array}{l}\text { Munseom } \\
\left(33^{\circ} 13^{\prime} \mathrm{N}, 126^{\circ} 34^{\prime} \mathrm{E}\right)\end{array}$ & MUN & 5-10 m, semi-exposed, high-relief rocky reef, low turbidity $\left(1-2 \mathrm{mg} \mathrm{L}^{-1}\right)$, dense beds \\
\hline \multicolumn{3}{|l|}{ South Sea } \\
\hline $\begin{array}{l}\text { Yeosu } \\
\left(34^{\circ} 27^{\prime} \mathrm{N}, 127^{\circ} 48^{\prime} \mathrm{E}\right)\end{array}$ & YEO & $\begin{array}{l}\text { 3-5 m, semi-exposed, low-medium relief rocky reef with small patches of muddy sand, } \\
\text { high turbidity }\left(10-20 \mathrm{mg} \mathrm{L}^{-1}\right) \text {, scattered individuals-small patches }\end{array}$ \\
\hline $\begin{array}{l}\text { Mammuldo } \\
\left(34^{\circ} 38^{\prime} \mathrm{N}, 128^{\circ} 34^{\prime} \mathrm{E}\right)\end{array}$ & MAM & $\begin{array}{l}\text { 3-6 } \mathrm{m} \text {, sheltered, low-medium relief rocky reef, medium turbidity }\left(5-8 \mathrm{mg} \mathrm{L}^{-1}\right) \text {, small } \\
\text { patches }\end{array}$ \\
\hline \multicolumn{3}{|l|}{ East Sea } \\
\hline $\begin{array}{l}\text { Kori } \\
\left(35^{\circ} 19^{\prime} \mathrm{N}, 129^{\circ} 17^{\prime} \mathrm{E}\right)\end{array}$ & KOR & $\begin{array}{l}\text { 1-5 m, exposed rocky platforms with small patch of sand, low-medium turbidity } \\
\left(3-5 \mathrm{mg} \mathrm{L}^{-1}\right) \text {, scattered individuals-small patches }\end{array}$ \\
\hline $\begin{array}{l}\text { Wangdolcho } \\
\left(36^{\circ} 50^{\prime} \mathrm{N}, 130^{\circ} 02^{\prime} \mathrm{E}\right)\end{array}$ & WAN & 5-30 m, exposed, low-medium rocky reef, low turbidity $\left(1-3 \mathrm{mg} \mathrm{L}^{-1}\right)$, extensive dense beds \\
\hline $\begin{array}{l}\text { Dokdo } \\
\left(37^{\circ} 14^{\prime} \mathrm{N}, 131^{\circ} 51^{\prime} \mathrm{E}\right)\end{array}$ & DOK & 5-30 m, exposed, medium-high rocky reef, low turbidity $\left(1-2 \mathrm{mg} \mathrm{L}^{-1}\right)$, extensive dense beds \\
\hline
\end{tabular}

Twenty individuals were samples at each location, except Dokdo $(n=16)$. 
length, stipe diameter (at the point of immediately above holdfast), lamina length, lamina width (mid-1/3 of the central lamina), number of laterals, lateral length, and lateral width. All measurements were done for 16-20 mature individuals (per location) sampled only in the spring from all six locations.

\section{Genomic DNA extraction and RAPD assay}

The 16-20 sporophytes collected at each location were used for RAPD analysis. Frond disks $\left(25 \mathrm{~cm}^{2}\right)$ placed on the mid-2/3 of the central lamina were cut, washed with $1 \%$ sodium dodecyl sulfate in distilled water and then blotted dry. Each sample was preserved with silica gel in the dark until used.

DNA was extracted from $200 \mathrm{mg}$ of sample frond tissues ground in liquid nitrogen in a sterile mortar with a pestle. All extractions used the Pharmacia-Biotech kit (Accuprep Genomic DNA Extraction Kit; Bioneer Inc., Daejeon, Korea) according to the manufacture's instructions. DNA samples were quantitated using a NanoDrop ND-1000 Spectrophotometer (NanoDrop Technologies, Wilmington, DE, USA), also according to the manufacture's instructions.

All samples were initially screened with 200 random, decamer primers (10-mer kits A-J; Operon Technologies Inc., Huntsville, AL, USA) to check their ability to generate reproducible, informative DNA amplification products. For each sample and primer, duplicate reactions and reactions with DNAs extracted independently from the same sample were used.

DNA amplification reactions were performed in $20 \mu \mathrm{L}$ volumes containing $2.5 \mu \mathrm{L}$ of $10 \times$ polymerase chain reaction (PCR) buffer, $2 \mu \mathrm{L}$ of deoxyribonucleoside triphosphate (dNTP) mixture (TaKaRa Bio Inc., Otsu, Japan), 0.5 $\mu \mathrm{M}$ of the primer, 1 ng of genomic DNA, 1 unit of Taq DNA polymerase (TaKaRa Bio Inc.) and distilled water. Amplifications were run in PTC-200 PCR System (MJ Research, San Francisco, CA, USA) and gave optimal bands with an initial denaturation step of $94^{\circ} \mathrm{C}$ for $5 \mathrm{~min}$ followed by 40 cycles of $94^{\circ} \mathrm{C}$ for $0.5 \mathrm{~min}, 40^{\circ} \mathrm{C}$ for $0.5 \mathrm{~min}, 72^{\circ} \mathrm{C}$ for $1 \mathrm{~min}$ and finally, $72^{\circ} \mathrm{C}$ for $5 \mathrm{~min}$, and stored at $4^{\circ} \mathrm{C}$. The concentration of DNA used was found to be optimal with respect to reproducibility and minimization of secondary ghost banding (technique background). Reaction mixes without DNA were run as blanks in all RAPD amplifications. Nine primers gave optimally reproducible polymorphic bands and were thereby selected for further analysis. Amplification products were resolved by $1.5 \%$ agarose gel electrophoresis in TBE buffer ( $45 \mathrm{mM}$ Tris-Borate and
$1 \mathrm{mM}$ EDTA) and visualized under ultraviolet light after ethidium bromide staining. Gels were photographed using a Kodak EDAS 200 digital camera documentation system (Kodak, New Haven, CT, USA).

\section{Data analysis}

To test whether each morphological character of $E$. cava is different among locations, a one-way ANOVA (Zar 1999) was performed. Before testing, data sets were checked for homogeneity of variances using Levene's test and fourth-root transformed if necessary. When differences were indicated, significantly different means were separated with Turkey's multiple comparison. To test the independence of each morphological character, product moment correlation was performed among all pairs of variables. A normalized Euclidean distance matrix was calculated using standardized data set on all morphological parameters, and a non-metric multidimensional scaling (nMDS) plot was constructed. A dendrogram for hierarchical clustering of the six locations was also constructed using a group average linkage method. SIMPER (similarity of percentages) was performed to identify which morphological characteristics contributed most to the observed patterns. All analyses on morphological characters were performed using PRIMER v5 (Clarke and Gorley 2001) and Minitab v13.

For RAPD analysis, only reproducible and distinctively well-resolved bands were scored for resolving. The presence of a band was scored as 1 and absence was scored as 0 . After scoring, a matrix of RAPD phenotypes was then assembled across all individuals and locations. For each location, the gene diversity, measured as the expected heterozygosity $(H)$ averaged over loci (Nei 1978), was calculated using the program POPGENE 1.32 (Yeh et al. 1999).

To estimate components of variance among and within locations, gene frequencies were analyzed using a nested analysis of variance (analysis of molecular variance, AMOVA) (Excoffier et al. 1992). AMOVA allowed us to assess the partitioning of RAPD variation and sporophytic populations of E. cava at different hierarchical levels and test for significance against null hypothesis of no structure. AMOVA was done using Arlequin ver. 3.0 software (Excoffier et al. 2005).

The gene flow $\left(\mathrm{N}_{\mathrm{m}}\right.$, the number of migrants per generation) (Whitlock and McCauley 1999) was approximated as

$$
\mathrm{N}_{\mathrm{m}}=\left(\frac{1}{4}\right)\left[\left(\frac{1}{\Phi_{\mathrm{ST}}}\right)-1\right]
$$



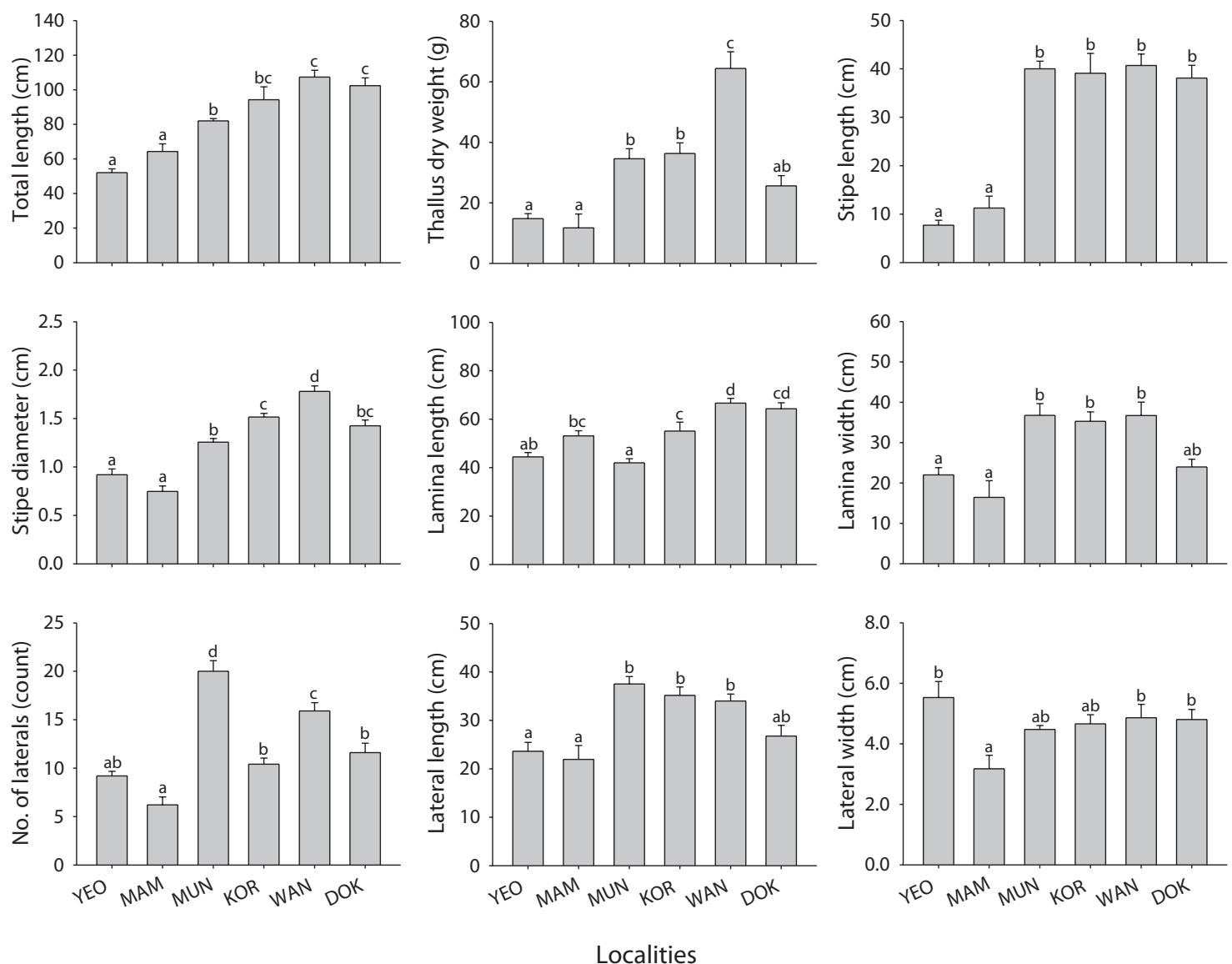

Fig. 3. Comparison of the nine morphological charters in the six locations. Data are mean $\pm 1 \mathrm{SE}$. Bars with different letters are significantly different $(p<0.05)$. YEO, Yeosu; MAM, Mammuldo; MUN, Munseom; KOR, Kori; WAN, Wangdolcho; DOK, Dokdo.

, where $\Phi_{\mathrm{ST}}$ values were available from a matrix of pairwise combinations produced by Arlequin ver. 3.0 software.

A genetic similarity dendrogram among locations was constructed using the matrix of pair-wise Nei's genetic distances calculated from the program POPGENE 1.32 and the unweighted pair-group method with arithmetical averages (UPGMA) (Sneath and Sokal 1973) algorithm. Data were also represented graphically in nMDS plots using a Euclidean distance matrix based on the presence / absence data set on RAPD bands. nMDS was done using PRIMER v5.

To test whether the magnitude of genetic difference was a function of distance between locations, the genetic distance $\left(\Phi_{\mathrm{ST}}\right)$ matrix and an among-location distance matrix generated from GPS co-ordinates (cf. Table 1) were analyzed using a Mantel test (Mantel 1967). In addition, we also conducted the Mantel test to test the significance of the correlation between the genetic distance $\left(\Phi_{\mathrm{ST}}\right)$ matrix and a Euclidean distance matrix generated from the morphological data set pooled within each location. All Mantel tests were done using the software Arlequin ver. 3.0.

\section{RESULTS}

\section{Spatial variability of morphology}

All morphological characteristics investigated were significantly different (one-way ANOVA, $p<0.005$ ) among locations (Fig. 3). In most morphological parameters, except lamina length, No. of laterals, and lateral width, Yeosu and Mammuldo showed significantly lower values than Munseom, Kori, Wangdolcho, and Dokdo (Turkey's multiple comparison, $\mathrm{p}<0.05$ ). In addition, most morphological characteristics showed considerable variation among locations. For example, total length differed by $49 \%$ between the means of the most extreme populations Wangdolcho and Yeosu. Similarly, there was $23 \%$ dry 
weight difference between the thallus biomass of individuals from Wangdolcho and Yeosu. Thallus dry weight was the most variable characteristics (coefficient of variation $[\mathrm{CV}]=61 \%$ ), whereas lateral width was the least variable one $(\mathrm{CV}=17 \%)$.

Most morphological characteristics were moderately to highly correlated to each other $(0.5<\mathrm{r}<1.0)$ (Table 2$)$. For example, total length was highly correlated to stipe length, stipe diameter, and lamina length $(r>0.8)$, and this could be somewhat expected as total length is the sum of stipe length and lamina length. In contrast, thallus dry weight was correlated to stipe diameter, lamina width, and lateral length with the value of $r>0.7$, suggesting that total length should not be a good single factor to scale the allometry of thallus biomass of E. cava.

The nMDS ordination based on all morphological characteristics (Fig. 4A) showed large separation (high dissimilarity) among locations (e.g., Wangdolcho and Yeosu) and very small separation (high similarity) among other locations (e.g., Yeosu and Mammuldo). There were also considerable within-location separations in a few places (e.g., Wangdolcho and Kori). In the dendrogram, the six locations were sharply separated into two groups (Yeosu and Mammuldo vs. Munseom, Kori, Wangdolcho, and Dokdo) (Fig. 4B).

Stipe length was by far the most important morphological parameters, on accounting for $\sim 19 \%$ of the dissimilarity in E. cava morphology between the two groups (i.e., Munseom, Kori, Wangdolcho, and Dokdo vs. Yeosu and Mammuldo) (Table 3). In contrast, most morphological parameters, except lateral width and lamina length, ranged from 10 to $12 \%$.

\section{Genetic variation by RAPD}

A total of 155 discernible and reproducible RAPD bands were generated with 9 selected primers across the 116 individuals of six locations, out of which 56 (36.1\%) were polymorphic (Table 4). The bands ranged in size from 370 to 2,900 bp. Number of bands produced per primer ranged from 10 to 27 with an average of 17.2, and that of polymorphic bands per primer lied between 3 and 10 with an average 6.2. Fig. 5 shows the RAPD profile of 20 individuals amplified with primer OPA-01.

Table 2. Correlation coefficients (Pearson product moment correlation) among the morphological characters on all the sampled individuals $(n=116)$

\begin{tabular}{cccccccccc}
\hline Character & TL & DW & SL & SD & LL & LW & NL & LAL & LAW \\
\hline TL & - & - & - & - & - & - & - & - \\
DW & 0.671 & - & - & - & - & - & - & - \\
SL & 0.905 & 0.613 & - & - & - & - & - & - \\
SD & 0.814 & 0.803 & 0.813 & - & - & - & - & - & - \\
LL & 0.808 & 0.509 & 0.481 & 0.552 & - & - & - & - & - \\
LW & 0.487 & 0.720 & 0.577 & 0.608 & 0.204 & - & - & - & - \\
NL & 0.388 & 0.613 & 0.558 & 0.487 & 0.026 & 0.575 & - & - \\
LAL & 0.488 & 0.759 & 0.610 & 0.617 & 0.161 & 0.781 & 0.677 & - & - \\
LAW & 0.096 & 0.277 & 0.104 & 0.320 & 0.054 & 0.241 & 0.302 & 0.355 \\
\hline
\end{tabular}

TL, total length; DW, thallus dry weight; SL, stipe length; SD, stipe diameter; LL, lamina length; LW, lamina width; NL, number of laterals; LAL, lateral length; LAW, lateral width.

Table 3. SIMPER results on the two groups (YEO and MAM vs. MUN, KOR, WAN and DOK)

\begin{tabular}{ccc}
\hline Morphological character & Contribution to dissimilarity (\%) & Consistency of contribution (dissimilarity / SD) \\
\hline Stipe length & 19.24 & 3.10 \\
Lamina width & 12.00 & 1.63 \\
Dry weight & 11.80 & 1.58 \\
Stipe diameter & 11.52 & 2.22 \\
Total length & 10.70 & 2.23 \\
Laterals length & 10.65 & 1.71 \\
No. of laterals & 10.51 & 1.48 \\
Laterals width & 7.33 & 1.34 \\
Lamina length & 6.25 & 1.55 \\
\hline
\end{tabular}

YEO, Yeosu; MAM, Mammuldo; MUN, Munseom; KOR, Kori; WAN, Wangdolcho; DOK, Dokdo; SD, standard deviation. 

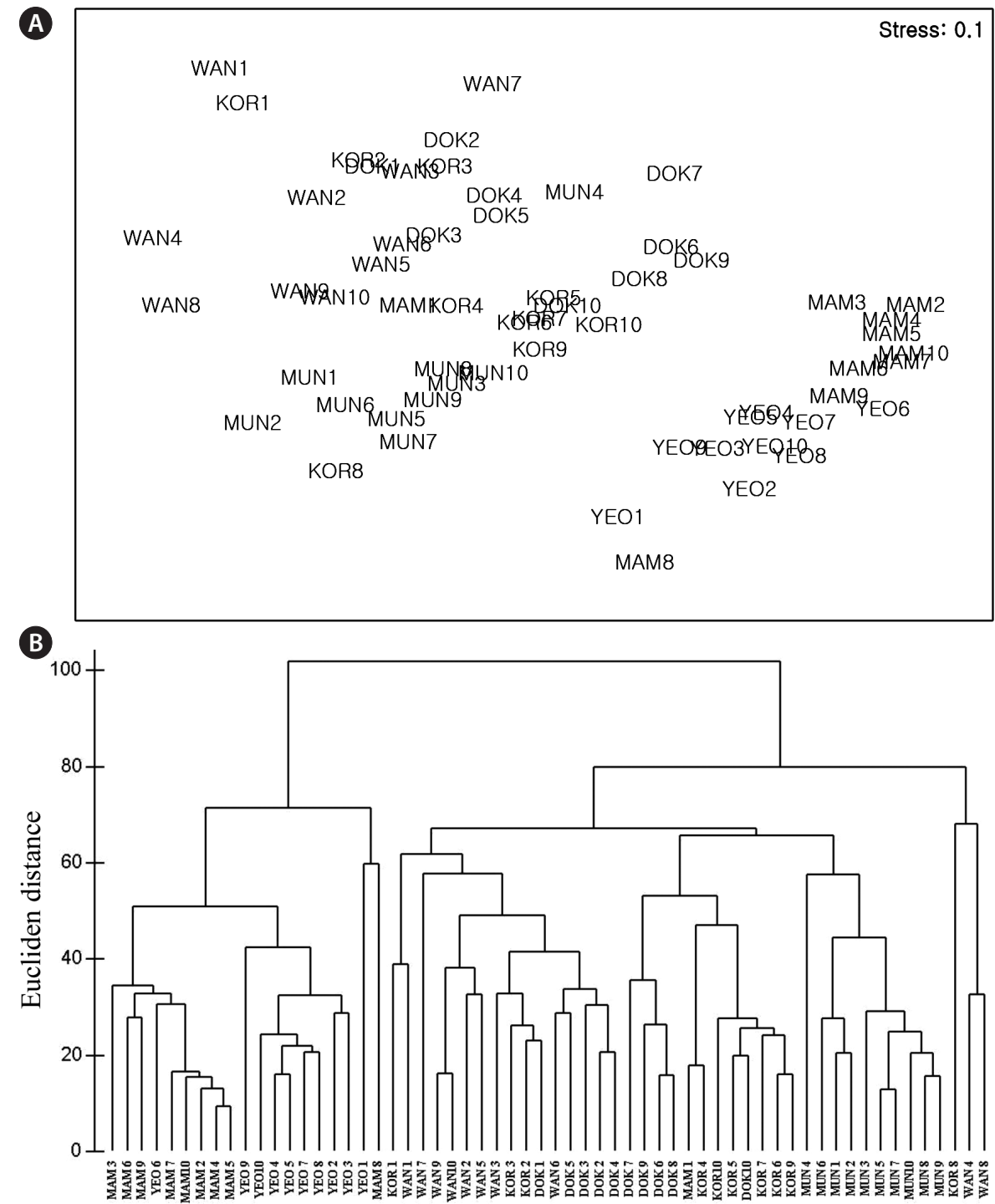

Localities

Fig. 4. Morphological analysis. (A) Non-metric multidimensional scaling plot, using a normalized Euclidean distance matrix based on standardized data set on all morphological characters. (B) Dendrogram for hierarchical clustering of the six locations, using a normalized Euclidean distance matrix based on standardized data set on all morphological characters. MUN, Munseom; YEO, Yeosu; MAM, Mammuldo; KOR, Kori; WAN, Wangdolcho; DOK, Dokdo.

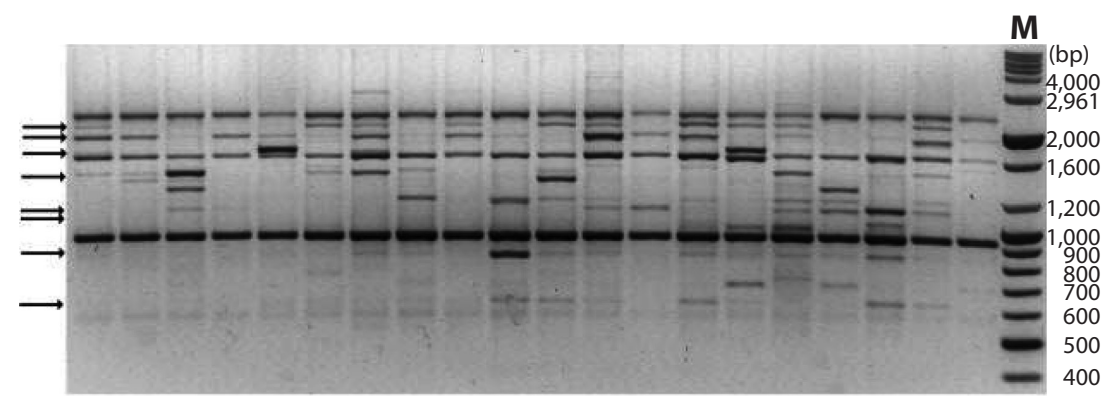

Fig. 5. Random amplified polymorphic DNA profile amplified with primer OPA-01 for 20 individuals of Ecklonia cava. Arrows on the left indicate polymorphic bands. The $\mathrm{M}$ lanes are Bioneer $100 \mathrm{bp}$ Ladder with each fragment size showing on the right. 
Table 4. Primer sequence, number of bands per primer, number of polymorphic bands per primer, and the approximate band size range

\begin{tabular}{lccccc}
\hline Primer & Sequence $\left(\mathbf{5}^{\prime}\right.$-3') & No. of bands & $\begin{array}{c}\text { No. of polymorphic } \\
\text { bands }\end{array}$ & $\begin{array}{c}\text { Percentage of } \\
\text { polymorphic bands (\%) }\end{array}$ & $\begin{array}{c}\text { Approx. band size } \\
\text { range (bp) }\end{array}$ \\
\hline OPA-01 & CAGGCCCTTC & 14 & 8 & 57.1 & $370-2,600$ \\
OPC-11 & AAAGCTGCGG & 10 & 4 & 40.0 & $420-1,300$ \\
OPD-02 & GGACCCAACC & 13 & 6 & 46.2 & $600-2,500$ \\
OPD-08 & GTGTGCCCCA & 17 & 7 & 41.2 & $700-2,900$ \\
OPE-03 & CCAGATGCAC & 18 & 7 & 38.9 & $430-1,700$ \\
OPH-03 & AGACGTCCAC & 16 & 3 & 18.8 & $500-1,600$ \\
OPI-04 & CCGCCTAGTC & 14 & 5 & 35.7 & $390-2,100$ \\
OPI-07 & CAGCGACAAG & 26 & 10 & 38.5 & $570-2,100$ \\
OPJ-04 & CCGAACACGG & 27 & 6 & 22.2 & $600-2,900$ \\
Total & & 155 & 56 & 36.1 & $370-2,900$ \\
Mean & & 17.2 & 6.2 & 37.6 & \\
\hline
\end{tabular}

Table 5. RAPD diversity $(H)$

\begin{tabular}{|c|c|c|c|c|c|c|}
\hline Primers & MUN & YEO & MAM & KOR & WAN & DOK \\
\hline OPA-01 & 0.240 & 0.273 & 0.183 & 0.200 & 0.142 & 0.196 \\
\hline OPC-11 & 0.177 & 0.180 & 0.153 & 0.304 & 0.201 & 0.181 \\
\hline OPD-02 & 0.170 & 0.304 & 0.196 & 0.191 & 0.201 & 0.249 \\
\hline OPD-08 & 0.224 & 0.273 & 0.259 & 0.276 & 0.190 & 0.065 \\
\hline OPE-03 & 0.154 & 0.206 & 0.223 & 0.224 & 0.243 & 0.299 \\
\hline OPH-03 & 0.196 & 0.123 & 0.257 & 0.110 & 0.273 & 0.177 \\
\hline OPI-04 & 0.226 & 0.239 & 0.145 & 0.097 & 0.226 & 0.247 \\
\hline OPI-07 & 0.185 & 0.203 & 0.159 & 0.182 & 0.148 & 0.260 \\
\hline OPJ-04 & 0.311 & 0.226 & 0.152 & 0.148 & 0.218 & 0.162 \\
\hline Mean & 0.209 & 0.225 & 0.192 & 0.192 & 0.205 & 0.204 \\
\hline
\end{tabular}

RAPD, random amplified polymorphic DNA; MUN, Munseom; YEO, Yeosu; MAM, Mammuldo; KOR, Kori; WAN, Wangdolcho; DOK, Dokdo.

Table 6. AMOVA for the six locations using 155 RAPD bands

\begin{tabular}{lrrrrr}
\hline Source of variation & d.f. & \multicolumn{1}{c}{ SS } & \multicolumn{1}{c}{ MS } & Variance components & Percentage of variation (\%) \\
\hline Among locations & 5 & 921.328 & 144.246 & $8.67697^{* * *}$ & 34.2 \\
Within location & 110 & $1,838,137$ & 12.198 & $16.71034^{* * *}$ & 65.8 \\
Total & 115 & $2,759,466$ & & & \\
\hline
\end{tabular}

RAPD, random amplified polymorphic DNA.

$* * * p<0.001$.

Table 7. Pair-wise $\Phi_{\text {ST }}$ (below diagonal) and $\mathrm{N}_{\mathrm{m}}$ (above diagonal) between the six locations

\begin{tabular}{ccccccc}
\hline Population & MUN & YEO & MAM & KOR & WAN & DOK \\
\hline MUN & - & $0.501^{* * *}$ & $0.402^{* * *}$ & $0.363^{* * *}$ & $0.499^{* * *}$ & $0.484^{* * *}$ \\
YEO & $0.333^{* * *}$ & - & $0.525^{* * *}$ & $0.430^{* * *}$ & $0.463^{* * *}$ & $0.514^{* * *}$ \\
MAM & $0.383^{* * *}$ & $0.323^{* * *}$ & - & $0.550^{* * *}$ & $0.453^{* * *}$ & $0.467^{* * *}$ \\
KOR & $0.408^{* * *}$ & $0.367^{* * *}$ & $0.312^{* * *}$ & - & $0.595^{* * *}$ & $0.511^{* * *}$ \\
WAN & $0.334^{* * *}$ & $0.351^{* * *}$ & $0.355^{* * *}$ & $0.296^{* * *}$ & - & $0.647^{* * *}$ \\
DOK & $0.341^{* * *}$ & $0.327^{* * *}$ & $0.349^{* * *}$ & $0.328^{* * *}$ & $0.279^{* * *}$ & - \\
\hline
\end{tabular}

MUN, Munseom; YEO, Yeosu; MAM, Mammuldo; KOR, Kori; WAN, Wangdolcho; DOK, Dokdo.

*** $\mathrm{p}<0.001$ 

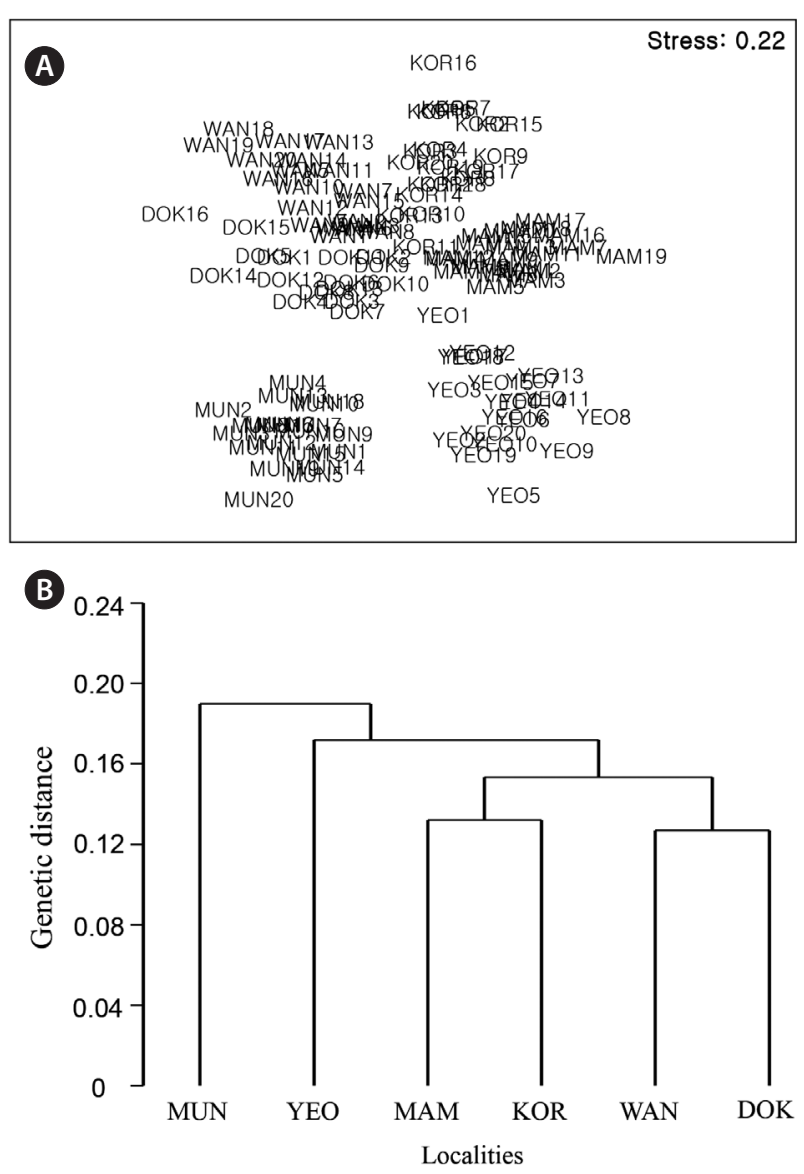

Fig. 6. Random amplified polymorphic DNA (RAPD) analysis. (A) Non-metric multidimensional scaling plot, using a Euclidean distance matrix based on the presence / absence data set on RAPD bands. (B) Genetic similarity dendrogram among the six populations, using a matrix of pair-wise Nei's genetic distances. MUN, Munseom; YEO, Yeosu; MAM, Mammuldo; KOR, Kori; WAN, Wangdolcho; DOK, Dokdo.

Primers varied in their capability to detect variation within each location, with $H$ ranging from 0.065 (primer OPD-08, Dokdo) to 0.311 (primer OPJ-04, Munseom), suggesting that a sufficient number of primers are essential for a reliable evaluation of the species genetic variation (Table 5). On average over all primers, Mammuldo and Kori exhibited the lowest level of genetic diversity $(H=0.192)$, whereas Yeosu showed the highest value $(H$ $=0.225)$.

The variance components of within and between locations detected with AMOVA were $65.8 \%$ and $34.2 \%$ of the total variance, respectively, which were both significant at a probability less than 0.001 (Table 6). Hence, it seems clear that while most of the variation is partitioned within populations, there is still considerable variation between populations.
A matrix of pair-wise $\Phi_{\text {ST }}$ values, the significance and the effective number of migrants $\left(\mathrm{N}_{\mathrm{m}}\right)$ between populations are presented in Table 7. Values of $\Phi_{\mathrm{ST}}$ ranged from 0.279 (between Wangdolcho and Dokdo) to 0.408 (between Munseom and Kori) and were all significant at 0.001 level, suggesting that all locations may be considered different from each other, with Munseom and Kori being the most different from the others and Wangdolcho and Dokdo being the most similar. Values of $\mathrm{N}_{\mathrm{m}}$ ranged from 0.363 to 0.647 , but the majority of the values lied between 0.4 and 0.6 , which indicated a moderate gene flow between the six locations.

The nMDS ordination based on the RAPD presence / absence data (Fig. 6A) showed large separation (high dissimilarity) among locations (e.g., Wangdolcho and Munseom) and very small separation (high similarity) among other locations (e.g., Wangdolcho and Dokdo). In the dendrogram based on Nei's genetic distances, the six locations were distinctively separated into three groups (Mammuldo, Kori, Wangdolcho, and Dokdo vs. Munseom vs. Yeosu) (Fig. 6B).

There was no correlation between genetic distance $\left(\Phi_{\mathrm{ST}}\right)$ and geographical distance between locations (Mantel test, $\mathrm{r}=0.24, \mathrm{p}=0.18$ ). Likewise, the correlation between genetic distance $\left(\Phi_{\mathrm{ST}}\right)$ and morphological dissimilarity between locations was not significant (Mantel test, $\mathrm{r}=0.27, \mathrm{p}=0.17$ ).

\section{DISCUSSION}

Our quantitative multivariate analyses indicated that, when all the morphological parameters were considered, a distinct hierarchy to the morphological variation. Stipe length was identified as the parameter most responsible for the hierarchical structure. Two phenetically distinct groupings of plants exist, one group with shorter stipe (Yeosu and Mammuldo) and the other with longer stipe (Munseom, Kori, Wangdolcho, and Dokdo). Such phenotypes of E. cava adopting different stipe lengths have also been reported in many previous studies. For example, the small type sporophytes with short stipe of E. cava retained the same phenotypes after transplantation into larger type with a long stipe to a locality with lower temperature conditions (Serisawa et al. 2002b).

Substantial morphological variation is a common phenomenon in kelp species (Lubchenco and Cubit 1980, Camus and Ojeda 1992, Serisawa et. al. 2002a, Duggins et al. 2003, Wernberg et al. 2003) in response to differences in ocean climate. Stipe length of E. cava, in particular, has 
been observed to vary, likely in response to seawater temperature (see reviews in Serisawa et al. 2002a). This, however, may not be the case of E. cava involved in this study since many physicochemical factors including seawater temperature vary between the two groups. For example, Yeosu and Mammuldo are located in turbid (suspended sediment, $>5 \mathrm{mg} \mathrm{L}^{-1}$ ) nearshore areas and most $E$. cava habitats are sheltered or semi-exposed, whereas Munseom, Kori, Wangdolcho, and Dokdo are located in clear (suspended sediment, $<5 \mathrm{mg} \mathrm{L}^{-1}$ ) nearshore or offshore areas and most $E$. cava habitats are semi-exposed or exposed. Furthermore, stipe length of E. cava showed the highest correlation with stipe diameter. Fowler-Walker et al. (2006) argued from observational and experimental studies that $E$. radiata sporophytes at sheltered sites adopt a thallus with larger surface area, and have longer, wider but thinner laterals. These characteristics maximize surface area for nutrient uptake and light harvesting compared to sporophytes at exposed sites that adopt shorter, narrower and thicker laterals. The thicker stipes and fewer laterals may decrease drag and prevent breakage. In this case, the two phenotypes of E. cava adopting different stipe lengths and stipe thickness may result from combined abiotic factors such as turbidity and wave action. The evidence is only correlative; this study was not designed to identify the cause of spatial variations in stipe length but to describe broad-scale patterns of morphological variation in E. cava over a large portion of geography.

RAPD markers, along with appropriate statistical procedures, are suitable for genetic variation analyses at both intra- and inter-population levels (e.g., Faugeron et al. 2001, Bouza et al. 2006, Larkin et al. 2006). In the present study, the marker technology has been employed in combination with morphological characteristics to detect genetic variation and population structure of E. cava from Korea, and has once again demonstrated its usefulness in gaining information quickly in a previously less-studied species. The level of diversity $(H)$ detected here in E. cava is generally lower than in Mazzaella laminarioides (Bory) Fredericq (Faugeron et al. 2001) and Gelidium canariense (Grunow) Seoane-Camba ex Haroun, Gil-Rodríguez, Diaz de Castro et Prud'Homme van Reine (Bouza et al. 2006). This comparison may provide other interesting questions of the capability of spore dispersal between subtidal kelps and lower intertidal reds.

Genetic variation and partitioning among and within populations of a plant species are determined by a number of factors, of which reproductive biology system (outcrossing vs. self-fertilization) is most important (Hamrick and Loveless 1989). As shown by the AMOVA, the high level of RAPD variation in E. cava was observed at the intrapopulation level. In addition, $\Phi_{\mathrm{ST}}$ values between population pairs reveal significant interpopulational differentiation. In addition, the number of migrants estimated among populations $\left(\mathrm{N}_{\mathrm{m}}, 0.363-0.647\right)$ was much lower than tropical trees (>1.0) (Reis 1996). These results suggest interpopulation dispersal in E. cava is limited, compared to terrestrial plants, even though their biology and environments are completely different. In fact, seaweeds are generally considered poor dispersals because spore survival is generally limited to a few days (Santelices 1990, Sosa and García-Reina 1993). The restricted gene flow in E. cava likely results from the limited long distance dispersal of spores, gametes, or drifting reproductive fragments.

The ordination based on the RAPD presence / absence data and the dendrogram based on Nei's genetic distances indicate a distinct hierarchy to the genetic variation. Three genetically distinct groupings (Mammuldo, Kori, Wangdolcho, and Dokdo vs. Munseom vs. Yeosu) were recognized, not consistent with the quantitative multivariate analyses on morphological characteristics. Hence, no correlation was found between genetic distance $\left(\Phi_{\mathrm{ST}}\right)$ and morphological dissimilarity between locations.

The environmental differentiations rather than genetic basis may be one reason for morphological variation. Morphological variation occurs over a broad range of physical environments (Sultan 2001). Within its geographic range, E. cava exhibits considerable morphological variation among plants, apparently correlated with local environmental conditions. For example, in the southeast coast of Japan (Serisawa et al. 2002a), E. cava sporophytes express long blades and short stipes in Tei, Tosa Bay (southern Japan) and short blades and long stipes in Nebeta Bay, Shimoda (central Japan), likely in response to water temperature. Likewise, E. cava also possesses life-history strategies suitable for diverse habitats it occupies. For example, in Tosa Bay where water temperature is high $\left(15-29^{\circ} \mathrm{C}\right)$, E. cava has a short life span (3 y), whereas in Nebeta Bay where water temperature is low $\left(13-25^{\circ} \mathrm{C}\right)$, E. cava has a long life span $(5 \mathrm{y})$ (Serisawa et al. 2001).

The low correlation between locations is shown in many terrestrial pants such as tropical evergreen tree ( $\mathrm{Li}$ et al. 2008), barley (Lund 2002), and potato (Veteläinen et al. 2005) and may be explained by the different molecular markers and morphological characteristics (Collignon et al. 2002, Navarro et al. 2005). Molecular markers are usually considered selectively neutral (Strauss et al. 1992) 
and do not necessarily reflect the diversity in functional characteristics (Karhu et al. 1996, Van Hintum and Van Treuren 2002). Furthermore, such a weak correlation implies the differences in the degree of genomic coverage between molecular markers and morphological characteristics (Veteläinen et al. 2005). Therefore, both morphological and molecular assays are comparably important in population diversity studies in E. cava.

Likewise, there was no correlation between genetic distance $\left(\Phi_{\mathrm{ST}}\right)$ and geographical distance between locations. Many studies (e.g., Miller et al. 2000, Roberson and Coyer 2004) have shown kelp to express genetic differentiation in response to differences in ocean climate. As pointed out by Rice et al. (1985), ocean climate is not continuously distributed in space over a large geographical scale. However, the genetic distance $\left(\Phi_{\mathrm{ST}}\right)$ of the adjacent area populations were closer (e.g., Wangdolcho and Dokdo, Kori and Wangdolcho). This showed that ocean current in this area may also influence the dispersal of spores. As mentioned, Tsushima Warm Current (TWC) enters the South Sea from Jeju Island and moves eastward through the Korean Strait. And the cold shelf water originating from the Yellow Sea also enters the South Sea and moves eastward along the coast (Chang et al. 2000, Lee and Chao 2003). In fact, gene flow $\left(N_{m}\right.$, the number of migrants per generation) was moving more in adjacent area populations (Table 7). Therefore, this RAPD data demonstrated that local populations of E. cava gradually spread from Jeju Island to Dokdo by ocean current.

In conclusion, we report the first assessment on the genetic diversity of E. cava populations based on combined analyses of RAPD and morphological data. This study suggests environmentally specific forms of $E$. cava in Korea reflect the local oceanic characteristics such as open sea and closed bay. Also, RAPD results reflect the direction Tsushima Warm Current, by which spores and zygotes can be easily carried. Both morphological and molecular assays could be used as complementary methods in describing the population diversity in the species.

\section{ACKNOWLEDGEMENTS}

We thank Jong-Wook Lee for field assistance and preparation of experiment. This research was a part of the project titled "Long-term change of structure and function in marine ecosystem of Korea" funded by the Ministry of Oceans and Fisheries, Korea. This research also was supported by project PE9931A of Korea Institute of Ocean Science \& Technology (KIOST).

\section{REFERENCES}

Bouza, N., Caujapé-Castells, J., González-Peréz, M. Á. \& Sosa, P. A. 2006. Genetic structure of natural populations in the red algae Gelidium canariense (Gelidiales, Rhodophyta) investigated by random amplified polymorphic DNA (RAPD) markers. J. Phycol. 42:304-311.

Camus, P. A. \& Ojeda, F. P. 1992. Scale-dependent variability of density estimates and morphometric relationships in subtidal stands of the kelp Lessonia trabeculata in northern and central Chile. Mar. Ecol. Prog. Ser. 90:193-200.

Chang, K. -I., Suk, M. -S., Pang, I. -C. \& Teague, W. J. 2000. Observations of the Cheju Current. J. Korean Soc. Oceanogr. 35:129-152.

Chung, H., Cho, K. W., Chung, K. H., Kim, J. H., Shin, J., Seo, Y., Kang, J. -S. \& Lee, I. K. 1998. Ecological characteristics of algal whitening in coastal zone of Seogwipo area, Cheju Island. Algae 13:361-374.

Clarke, K. R. \& Gorley, R. N. 2001. Primer v6: user manual/ tutorial. PRIMER-E, Plymouth.

Collignon, A. -M., Van de Sype, H. \& Favre, J. -M. 2002. Geographical variation in random amplified polymorphic DNA and quantitative traits in Norway spruce. Can. J. For. Res. 32:266-282.

Coyer, J. A., Olsen, J. L. \& Stam, W. T. 1997. Genetic variability and spatial separation in the sea palm kelp, Postelsia palmaeformis (Phaeophyceae) as assessed with M13 fingerprints and RAPDs. J. Phycol. 33:561-568.

Duggins, D. O., Eckman, J. E., Siddon, C. E. \& Klinger, T. 2003. Population, morphometric and biomechanical studies of three understory kelps along a hydrodynamic gradient. Mar. Ecol. Prog. Ser. 265:57-76.

Excoffier, L., Laval, G. \& Schneider, S. 2005. Arlequin (version 3.0): an integrated software package for population genetics data analysis. Evol. Bioinform. Online 1:47-50.

Excoffier, L., Smouse, P. E. \& Quattro, J. M. 1992. Analysis of molecular variance inferred from metric distances among DNA haplotypes: application to human mitochondria DNA restriction data. Genetics 131:479-491.

Faugeron, S., Valero, M., Destombe, C., Martínez, E. A. \& Correa, J. A. 2001. Hierarchical spatial structure and discriminant analysis of genetic diversity in the red alga Mazzaella laminarioides. J. Phycol. 37:705-716.

Fowler-Walker, M. J., Wernberg, T. \& Connell, S. D. 2006. Differences in kelp morphology between wave sheltered and exposed localities: morphologically plastic or fixed traits? Mar. Biol. 148:755-767.

Frankham, R. 1996. Relationship of genetic variation to population size in wildlife. Conserv. Biol. 10:1500-1508.

Frankham, R., Ballou, J. D. \& Briscoe, D. A. 2002. Introduction 
to conservation genetics. Cambridge University Press, Cambridge, 638 pp.

Gómez, P. I. \& González, M. A. 2001. Genetic polymorphism in eight Chilean strains of the carotenogenic microalga Dunaliella salina Teodoresco (Chlorophyta). Biol. Res. 34:23-30.

Gómez, P. I. \& González, M. A. 2004. Genetic variation among seven strains of Dunaliella salina (Chlorophyta) with industrial potential, based on RAPD banding patterns and on nuclear ITS rDNA sequences. Aquaculture 233:149162.

Hadrys, H., Balick, M. \& Schierwater, B. 1992. Applications of random amplified polymorphic DNA (RAPD) in molecular ecology. Mol. Ecol. 1:55-63.

Hamrick, J. L. \& Loveless, M. D. 1989. The genetic structure of tropical tree population: associations with reproductive biology. In Bock, J. H. \& Linhart, Y. B. (Eds.) The Evolutionary Ecology of Plants. Westview Press, Boulder, CO, pp. 129-146.

Kang, R. -S. 2010. A review of destruction of seaweed habitats along the coast of Korean Peninsula and its consequences. Bull. Fish. Res. Agency 32:25-31.

Kang, R. -S., Je, J. -G. \& Sohn, C. -H. 1993. Summer algal communities in the rocky shore of the South Sea of Korea. II. Subtidal communities. Bull. Korean Fish. Soc. 26:182197 (in Korean).

Kang, R. -S., Won, K. -S., Hong, K. -P. \& Kim, J. -M. 2001. Population studies on the kelp Ecklonia cava and Eisenia bicyclis in Dokdo, Korea. Algae 16:209-215.

Karhu, A., Hurme, P., Karjalainen, M., Karvonan, P., Kärkkäinen, K., Neale, D. \& Savolainen, O. 1996. Do molecular markers reflect patterns of differentiation in adaptive traits of conifers? Theor. Appl. Genet. 93:215-221.

Kirkman, H. 1981. The first year in the life history and the survival of the juvenile marine macrophyte, Ecklonia radiata (Turn.) J. Agardh. J. Exp. Mar. Biol. Ecol. 55:243254.

Kusumo, H. T. \& Druehl, L. D. 2000. Variability over space and time in the genetic structure of the winged kelp Alaria marginata. Mar. Biol. 136:397-409.

Largo, D. B. \& Ohno, M. 1993. Constructing an artificial seaweed bed. In Ohno, M. \& Critchley, A. T. (Eds.) Seaweed Cultivation and Marine Ranching. Japan International Cooperative Agency, Tokyo, pp. 113-130.

Larkin, P., Quevedo, E., Salinas, S., Parker, J., Storey, K. \& Hardegree, B. 2006. Genetic structure of two Thalassia testudinum populations from the south Texas Gulf coast. Aquat. Bot. 85:198-202.

Lee, H. -J. \& Chao, S. -Y. 2003. A climatological description of circulation in and around the East China Sea. Deep Sea
Res. Part II Top. Stud. Oceanogr. 50:1065-1084.

Lee, Y. P. \& Kang, S. Y. 2001. A catalogue of the seaweeds in Korea. Cheju National University Press, Jeju, 662 pp.

Li, F., Gan, S., Weng, Q., Zhao, X., Huang, S., Li, M., Chen, S., Wang, Q. \& Shi, F. 2008. RAPD and morphological diversity among four populations of the tropical tree species Paramichelia baillonii (Pierre) Hu in China. For. Ecol. Manage. 255:1793-1801.

Lubchenco, J. \& Cubit, J. 1980. Heteromorphic life histories of certain marine algae as adaptations to variations in herbivory. Ecology 61:676-687.

Lund, B. 2002. Repatriation of Nordic barley germplasm. Ph. D. dissertation, The Royal Veterinary and Agricultural University, Department of Agricultural Sciences, Section of Plant Breeding and Crop Science, Copenhagen, Denmark, 264 pp.

Macinnis-Ng, C. M. O., Morrison, D. A. \& Ralph, P. J. 2005. Temporal and spatial variation in the morphophology of the brown macroalga Hormosira banksii (Fucales, Phaeophyta). Bot. Mar. 48:198-207.

Mantel, N. 1967. The detection of disease clustering and a generalized regression approach. Cancer Res. 27:209220.

Matson, P. G. \& Edwards, M. S. 2006. Latitudinal variation in stipe hollowing in Eisenia arborea (Phaeophyceae, Laminariales). Phycologia 45:343-348.

Miller, K. A., Olsen, J. L. \& Stam, W. T. 2000. Genetic divergence correlates with morphological and ecological subdivision in the deep-water elk kelp, Pelagophycus porra (Phaeophyceae). J. Phycol. 36:862-870.

Navarro, C., Cavers, S., Pappinen, A., Tigerstedt, P., Lowe, A. J. \& Merilä, J. 2005. Contrasting quantitative traits and neutral genetic markers for genetic resource assessment of Mesoamerican Cedrela odorata. Silvae Genet. 54:281292.

Nei, M. 1978. Estimation of average heterozygosity and genetic distance from a small number of individuals. Genetics 89:583-590.

Reis, M. S. 1996. Dinâmica da movimentação dos alelos: subsidios para conservação e manejo de populações naturais de plantas. Braz. J. Genet. 19:37-47.

Rice, E. L. \& Kenchington, T. J. 1990. Spatial variation patterns in the marine macroalgae Xiphophora gladiata ssp. gladiata (Phaeophyta). II. Morphological variation over large spatial scales. J. Phycol. 26:522-534.

Rice, E. L., Kenchington, T. J. \& Chapman, A. R. O. 1985. Intraspecific geographic-morphological variation patterns in Fucus distichus and F evanescens. Mar. Biol. 88:207-215.

Roberson, L. M. \& Coyer, J. A. 2004. Variation in blade morphology of the kelp Eisenia arborea: incipient speciation 
due to local water motion? Mar. Ecol. Prog. Ser. 282:115128.

Russell, G. 1978. Environment and form in the discrimination of taxa in brown algae. In Irvine, D. E. G. \& Price, J. H. (Eds.) Modern Approaches to the Taxonomy of Red and Brown Algae. Systematics Association Special Volume 10. Academic Press, New York, pp. 339-369.

Santelices, B. 1990. Patterns of reproduction, dispersal and recruitment in the seaweeds. Oceanogr. Mar. Biol. Annu. Rev. 28:177-276.

Serisawa, Y., Akino, H., Matsuyama, K, Ohno, M., Tanaka, J. \& Yokahama, Y. 2001. Comparison in biomass, density and age composition of Ecklonia cava populations in two localities with different tempaerature conditions. Suisanzoshoku 49:9-14.

Serisawa, Y., Akino, H., Matsuyama, K., Ohno, M., Tanaka, J. \& Yokahama, Y. 2002a. Morphometric study of Ecklonia cava (Laminariales, Phaeophyta) sporophytes in two localities with different temperature conditions. Phycol. Res. 50:193-199.

Serisawa, Y., Yokahama, Y., Aruga, Y. \& Tanaka, J. $2002 b$. Growth of Ecklonia cava (Laminariales, Phaeophyta) sporophytes transplanted to a locality with different temperature conditions. Phycol. Res. 50:201-207.

Sneath, P. H. A. \& Sokal, R. R. 1973. Numerical taxonomy: the principles and practice of numerical classification. Freeman, San Francisco, CA, 573 pp.

Sosa, P. A. \& García-Reina, G. 1993. Genetic variability of Gelidium canariensis (Rhodophyta) determined by isozyme electrophoresis. J. Phycol. 29:118-124.

Sosa, P. A., González-Peréz, M. A., Batista, F. \& Bouza, N. 2002. Conservación genética de especies vegetales amenazadas. In Baňares-Baudet, A. (Ed.) Biología de Conservacion de Plantas Amenazadas. Organismo Autonomo de Parques Nacionales, Madrid, pp. 133-160.
Strauss, S. H., Bousquet, J., Hipkins, V. D. \& Hong, Y. -P. 1992. Biochemical and molecular genetic markers in biosystematic studies of forest trees. New For. 6:125-158.

Sultan, S. E. 2001. Phenotypic plasticity and ecological breadth in plants. Am. Zool. 41:1599.

Sunnucks, P. 2000. Efficient genetic markers for population biology. Trends Ecol. Evol. 15:199-203.

Terawaki, T. \& Arai, S. 2004. Eisenia and Ecklonia. In Ohno, M. (Ed.) Biology and Technology of Economic Seaweeds. Uchida Rokakuho Publishing Co. Ltd., Tokyo, pp. 133157.

Van Hintum, T. J. L. \& Van Treuren, R. 2002. Molecular markers: tools to improve genebank efficiency. Cell. Mol. Biol. Lett. 7:737-744.

Van Oppen, M. J. H., Klerk, H., De Graaf, M., Stam, W. T. \& Olsen, J. L. 1996. Assessing the limits of random amplified polymorphic DNAs (RAPDs) in seaweed biogeography. J. Phycol. 32:433-444.

Veteläinen, M., Gammelgård, E. \& Valkonen, J. P. T. 2005. Diversity of Nordic landrace potatoes (Solanum tuberos$u m$ L.) revealed by AFLPs and morphological characters. Genet. Resour. Crop Evol. 52:999-1010.

Wernberg, T., Coleman, M. A., Fairhead, V. A., Miller, S. \& Thomsen, M. S. 2003. Morphology of Ecklonia radiata (Phaeophyta: Laminarales) along its geographic distribution in south-western Australia and Australasia. Mar. Biol. 143:47-55.

Whitlock, M. C. \& McCauley, D. E. 1999. Indirect measures of gene flow and migration: Fst $\neq 1 /(4 \mathrm{Nm}+1)$. Heredity 82:117-125.

Yeh, F. C., Yang, R. \& Boyle, T. 1999. POPGENE version 1.32. Microsoft Window-based freeware for population genetic analysis. University of Alberta, Edmonton.

Zar, J. H. 1999. Biostatistical analysis. 4th ed. Prentice Hall, Inc., Upper Saddle River, NJ, 663 pp. 